American Journal of Applied Sciences 6 (9): 1658-1661, 2009

ISSN 1546-9239

(C) 2009 Science Publications

\title{
Effect of Germination on $\gamma$-Oryzanol Content of Selected Sarawak Rice Cultivars
}

\author{
Sie-Cheong Kiing, Pang-Hung Yiu, Amartalingam Rajan and Sie-Chuong Wong \\ Faculty of Agriculture and Food Sciences, \\ University Putra Malaysia Bintulu Campus, 97000 Bintulu, Malaysia
}

\begin{abstract}
Problem statement: Rice is rich in complex carbohydrates and beneficial bioactive compounds such as $\gamma$-Aminobutyric Acid (GABA), $\gamma$-oryzanol and vitamin. Several bioactive components are known to accumulate in rice during germination process. This study was to investigate the effect of germination process on $\gamma$-oryzanol levels in selected Sarawak local rice cultivars. Approach: Rice seeds were germinated for $4,8,12,16,18,20$ or $24 \mathrm{~h}$ at $25^{\circ} \mathrm{C}$ and samples were processed and analyzed for $\gamma$-oryzanol content. A partial extraction method was used for quantitative $\gamma$ oryzanol analysis. Results: Result showed $\gamma$-oryzanol concentrations in the rice cultivars varied from $0.099-0.340 \mathrm{mg} \mathrm{g}^{-1}$ on dry weight basis. Cultivars Udang Halus and Silah showed the highest concentration of $\gamma$-oryzanol after $16 \mathrm{~h}$ germination. Conclusion: The germination process exhibited diverse effects on the $\gamma$-oryzanol accumulation in rice and it was cultivar dependent.
\end{abstract}

Key words: rice, Oryza sativa L., $\gamma$-oryzanol, Sarawak

\section{INTRODUCTION}

Rice (Oryza sativa L.) is the main cereal food of the world, especially in Asian countries. In recent years, much attention has been on the health benefits of unpolished rice as a source of important bioactive compounds and nutrients. People are encouraged to consume unpolished rice (brown rice) instead of polished rice (white rice). It is because unpolished rice is an important source of bioactive compounds. Brown rice grains contain more nutritional components, such as $\gamma$-oryzanol, dietary fibers, phytic acids, vitamin $\mathrm{E}$, vitamin $\mathrm{B}$ and $\gamma$-aminobutyric acid (GABA), than the ordinary milled rice grains. These bio-functional components exist in the germ and bran layers which are removed during grain polishing or milling ${ }^{[1]}$.

Research indicates that cereal grains contain special phenolic compounds, such as ferulic acid esters of phytosterols (steryl ferulates) which have been identified in rice, corn, wheat, rye, barley and wild rice. These phenolic compounds have antioxidant, antimutagenic, anticancer and other positive effects as well as play an important role in maintaining health. Among these seeds, rice (Oryza sativa L.) exhibits the highest level of steryl ferulates ${ }^{[2]}$. The mixture of steryl ferulates found in rice is termed $\gamma$-oryzanol or more exactly is a group of ferulic acid esters of phytosterols and triterpene alcohols ${ }^{[3]}$. The sterol components of $\gamma$ oryzanol are primarily campesterol and sitosterol. The triterpene alcohol components are cycloartenol and 24methylene cycloartanol. Since $\gamma$-oryzanol is a mixture of ferulate esters with sterols or triterpenes, it can be divided to ferulic acid and triterpenes or sterols. Ferulic acid is initially converted from phenylalanine and tyrosine by enzymes ${ }^{[4]}$ and much of the ferulic acid occurs as esters in many plants, which may imply the pathway further undergoes conjugation with other molecules.

$\gamma$-oryzanol occurs in the unsaponifiable fraction of rice bran oil. It was originally considered a single compound but later was determined to be a mixture of ferulic acids esterified with normal sterols or triterpene alcohols. Ten components of $\gamma$-oryzanol identified in rice bran consist of ferulic acid and triterpene derived compounds, which are combined by an ester bond. Cycloartenyl ferulate, 24-methylenecycloartanyl ferulate and campesteryl ferulate are the three major components of $\gamma$-oryzanol in rice bran $^{[5-6]}$.

Several studies on germinated brown rice indicated that the germination process could improve nutritional

Corresponding Author: Yiu Pang Hung, Department of Basic Science Engineering, Faculty of Agriculture and Food Sciences, University Putra Malaysia Bintulu Campus, 97000 Bintulu, Malaysia

Tel: +6086-855432 Fax: +6086-855428 
values such as $\gamma$-aminobutyric acid (GABA), $\gamma$ oryzanol and vitamins ${ }^{[7,8]}$. Germinated brown rice or GBR is produced by soaking brown rice grains in water to promote germination. According to $\mathrm{Teo}^{[9]}$, Sarawak has more than 100 varieties of traditional rice and many of these are sold in the market throughout Sarawak. However, no reports have been documented on the effect of germination on bioactive compounds among rice cultivars in Sarawak. In this study, investigations were conducted to look into the effect of germination on $\gamma$-oryzanol levels of eight Sarawak rice cultivars.

\section{MATERIALS AND METHODS}

Materials: Eight rice cultivars Chelum, Sabak, Silah, Biris, Hitam, Boria, Udang Halus and Mamut2 were collected from southern Sarawak, Malaysia. Pure $\gamma-$ oryzanol standard was purchased from Tokyo Chemical Industry Co., Ltd. (Product Number: 00172). All chemicals used were analytical grade reagents.

Rice germination: Brown rice grains were soaked in water at $25^{\circ} \mathrm{C}$. They were allowed to undergo germination process for $4,8,12,16,18,20$ or $24 \mathrm{~h}$. The pregerminated brown rice samples were removed from the basin at the respective time intervals, dried, ground and analyzed for $\gamma$-oryzanol levels.

Determination of $\boldsymbol{\gamma}$-oryzanol: Total $\boldsymbol{\gamma}$-oryzanol content in brown rice were analyzed by using partial extraction methodology, as described by Lilitchan ${ }^{[10]}$. Rice cultivars were introduced into two identical vials (20 seeds each) and extracted with 4 and $8 \mathrm{~mL}$ of $\mathrm{n}$ hexane at room temperature by vigorous agitation on a vortex mixer (VELP SCIENTIFICA) for $1 \mathrm{~min}$. Solid and suspended bran was removed by centrifugation (KUBOTA 3110) at 2,500 rpm for $10 \mathrm{~min}$. The absorbance of the two supernatants was measured at $314 \mathrm{~nm}$ using a UV-vis spectrophotometer (Scinco S3100). The $\gamma$-oryzanol contents in the extracts were quantified against the standard curve. Total $\gamma$-oryzanol was calculated by solving two simultaneous equations:

$$
k=\left(\frac{x}{v}\right)\left(\frac{w}{y-x}\right)
$$

Where:

$\mathrm{k}=\mathrm{A}$ constant

$\mathrm{x}=$ The amount of $\gamma$-oryzanol in the extract $(\mathrm{g})$

$\mathrm{y}=$ The total amount of $\gamma$-oryzanol in the bran

$\mathrm{v}=$ The volume used for extraction $(\mathrm{mL})$

$\mathrm{w}=$ The weight of bran used for extraction
There are two unknowns ( $k$ and $y$ ), thus extraction of two identical samples with different volumes of solvent are necessary. In order to simplify the analysis and the calculation, the solvent used for the second extraction is double $\left(\mathrm{v}_{2}=2 \mathrm{v}_{1}\right)$ and the amount of solute in the two extracts are $x_{1}$ and $x_{2}$. Although the $k$ value for solid extraction is slightly varied, as the amount of solvent used for extractions is different, it is assumed that the change does not affect the accuracy of this study. Thus, by assuming $\mathrm{k}_{1}=\mathrm{k}_{2}$, total amount of $\gamma$ oryzanol (y) can be calculated:

$$
\begin{gathered}
\left(\frac{x_{1}}{v_{1}}\right)\left(\frac{w}{y-x_{1}}\right)=\left(\frac{x_{2}}{v_{2}}\right)\left(\frac{w}{y-x_{2}}\right) \\
y=\frac{x_{1} x_{2}}{2 x_{1}-x_{2}}
\end{gathered}
$$

\section{RESULTS}

Results showed that $\gamma$-oryzanol was found in all cultivars at all stages of the germination process (Table 1). Among the eight cultivars, cultivar Biris exhibited highest initial $\gamma$-oryzanol content $\left(0.270 \mathrm{mg} \mathrm{g}^{-1}\right.$ of dry weight) while the cultivar with lowest $\gamma$ oryzanol content was Udang Halus $\left(0.099 \mathrm{mg} \mathrm{g}^{-1}\right.$ of dry weight).

After germination of $24 \mathrm{~h}$, only three cultivars retained or showed slight increases in $\gamma$-oryzanol content (Sabak, Silah and Hitam). The rest of the cultivars showed reduction in $\gamma$-oryzanol content compared to pre-germination levels. The cultivar which showed highest $\gamma$-oryzanol content after $24 \mathrm{~h}$ was Silah (0.264 $\mathrm{mg} \mathrm{g}^{-1}$ of dry weight) meanwhile the cultivar with lowest $\gamma$-oryzanol content was Udang Halus (0.077 $\mathrm{mg} \mathrm{g}^{-1}$ of dry weight).

However, the results of analysis at 4-hourly intervals showed some trends in $\gamma$-oryzanol content. The $\gamma$-oryzanol level in the rice varied with different duration of germination (Fig. 1). Although the $\gamma$ oryzanol content after $24 \mathrm{~h}$ germination does not show significant increases for all cultivars studied, significant increments in $\gamma$-oryzanol content during the $24 \mathrm{~h}$ duration did occur except for Boria and Biris where the initial $\gamma$-oryzanol values was the highest. Each cultivar had different levels of $\gamma$-oryzanol at different germination duration within the $24 \mathrm{~h}$. The $\gamma$-oryzanol content of the different cultivars in this study did not increase directly with germination duration but showed significant variation among cultivars (Fig. 1). 
Table 1: $\gamma$-oryzanol content in eight traditional rice cultivars from Sarawak

\begin{tabular}{lll}
\hline & $\gamma$-oryzanol content $\left(\mathrm{mg} \mathrm{g}^{-1}\right)$ \\
Rice cultivar & Initial & 24 h germination \\
\hline Chelum & 0.182 & 0.165 \\
Sabak & 0.130 & 0.134 \\
Silah & 0.224 & 0.264 \\
Biris & 0.270 & 0.121 \\
Hitam & 0.103 & 0.132 \\
Boria & 0.247 & 0.077 \\
Udang halus & 0.099 & 0.067 \\
Mamut 2 & 0.103 & 0.078 \\
\hline
\end{tabular}

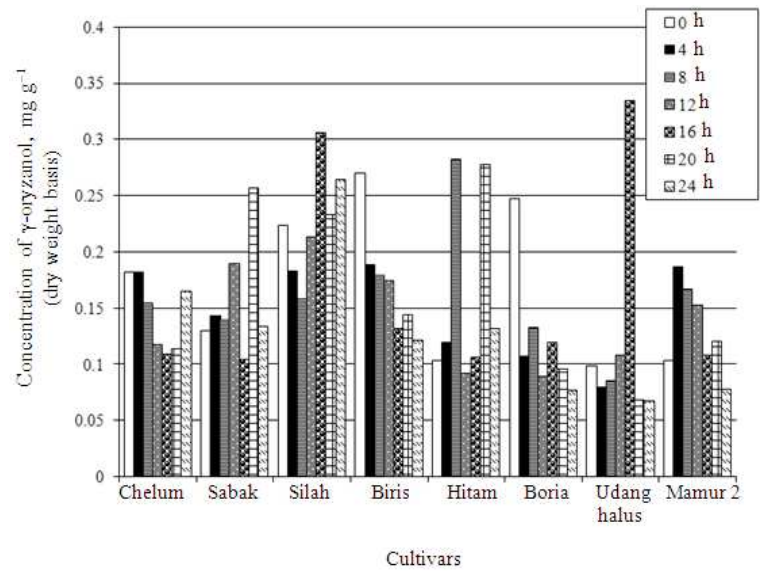

Fig. 1: $\gamma$-oryzanol Content in eight rice cultivars at different germination duration

\section{DISCUSSION}

Germination time promoted increase in bioactive component concentration in at least five of the eight cultivars studied. Bioactive components such as $\gamma$ oryzanol, $\alpha$-tocopherol, $\gamma$-aminobutyric acid (GABA) have been reported at high levels in germinated brown rice $^{[11]}$. During the process of germination, saccharification occurs, breaking complex carbohydrates into simple sugars and softening the nutritive tissue surrounding the embryo of plants. Hydrolytic enzymes are thus activated, which increases the amount of digestible vitamins, oligosaccharides, minerals and amino acids by decomposing starch, non starch polysaccharides and proteins. The decomposition of the high molecular weight polymers during germination leads to the generation of bio-functional substances ${ }^{[12]}$. From the results obtained, the different rice cultivar had different concentrations of $\gamma$-oryzanol within the $24 \mathrm{~h}$ duration of germination. Concentrations of $\gamma$-oryzanol in GBR are cultivar and germination duration dependent. This may be attributed to genetic and environmental factors. Earlier studies have also show enormous variation in oryzanol content among genotypes ${ }^{[13-14]}$. Furthermore, the trends observed in different cultivars may also be due to different water uptake rates by the different rice seeds ${ }^{[15]}$.

\section{CONCLUSION}

As $\gamma$-oryzanol plays an important role health and nutrichemical industry, it is crucial that methods that maximize the extraction of $\gamma$-oryzanol from rice be developed. Results do indicate that germination can increase $\gamma$-oryzanol content in certain rice cultivars.

\section{ACKNOWLEDGEMENTS}

The author wish to thank the UPM for permission to publish the results of this study. This research was supported by the Science Fund Scheme Grant No: 0201-04-SF0509, under the Ministry of Science, Technology and Innovation, Malaysia.

\section{REFERENCES}

1. Sawaddiwong, R., A. Jongjareonrak and S. Benjakul, 2008. Phenolic content and antioxidant activity of germinated brown rice as affected by germination temperature and extraction solvent. http://www.kmitl.ac.th/science/sci_journal/files/02 4\%20phenolic.pf1.doc

2. Moreau, R.A., M.J. Powell, K.B. Hicks and R.A. Norton, 1998. A Comparison of the Levels of FerulatePhytosterol Esters in Corn and Other Seeds. In: Advances in Plant Lipid Research, Sanchez, J., E. Cerda-Olmedo and E. Matinez-Force (Eds.). Universidad de Sevilla, Sevilla, Spain, pp: 472-474.

3. Nyström, L., 2007. Occurrence and properties of steryl ferulates and glycosides in wheat and rye. $\mathrm{PhD}$ thesis. University of Helsinki. https://oa.doria.fi/handle/10024/29201

4. Graf, E., 1992. Antioxidant potential of ferulic acid. Free Rad. Biol. Med., 13: 435-448. http://www.ncbi.nlm.nih.gov/pubmed/1398220

5. Xu, Z. and J.S. Godber, 1999. Purification and identification of components of $\gamma$-oryzanol in rice bran oil. J. Agric. Food Chem., 47: 2724-2728. http://cat.inist.fr/?aModele=afficheN\&cpsidt=1213913

6. Fang, N., S. Yu and T.M. Badger, 2003. Characterization of triterpene alcohol and sterol ferulates in rice bran using LC-MS/MS. J. Agric. Food Chem., 51: 3260-3267. http://cat.inist.fr/?aModele $=$ afficheN\&cpsidt $=1479$ 2756 
7. Komatsuzaki, N., K. Tsukahara, H. Toyoshima, T. Suzuki, N. Shimizu and T. Kimura, 2007. Effect of soaking and gaseous treatment on GABA content in germinated brown rice. J. Food Eng., 78: 556-560.

http://cat.inist.fr/?aModele $=$ afficheN\&cpsidt $=1838$ 9979

8. Tian, S., K. Nakamura and H. Kayahara, 2004. Analysis of phenolic compounds in white rice, brown rice and germinated brown rice. J. Agric. Food Chem., 52: 4808-481. http://cat.inist.fr/?aModele $=$ afficheN\&cpsidt $=1596$ 4096

9. Teo, G.K., 2000. Rice Biodiversity of Sarawak. Proceeding of the Poster Paper Presented at the International Biodiversity Conference, Nov. 1-3, Sarawak Biodiversity Centre, Sarawak, pp: 1-3. http://www.doa.sarawak.gov.my/images/rice_biod v.pdf

10. Lilitchan, S., C. Tangprawat, K. Aryusuk, S. Krisnangkura, S. Chokmoh and K. Krisnangkura, 2008. Partial extraction method for the rapid analysis of total lipids and [gamma]-oryzanol contents in rice bran. Food Chem. 106: 752-759. DOI: 10.1016/j.foodchem.2007.06.052

11. Tungjaroenchai, W. and P. Hirunpong, 2008. Effect of germination on content of bioactive components in germinates brown rice of three rice cultivars. Proceeding of the 34th Congress on Science and Technology, Thailand, pp: 1-1.
12. Ohtsubo, K., K. Suzuki, Y. Yasui and T. Kasumi, 2005. Bio-functional components in the processed pre-germinated brown rice by a twin-screw extruder. J. Food Compos. Anal., 18: 303-316. DOI: $10.1016 /$ j.jfca.2004.10.003

13. Bergman, C.J. and Z. Xu, 2003. Genotype and environment effects on tocopherol, tocotrienol and $\gamma$-oryzanol contents of southern US. Rice. Cereal Chem., $\quad 80$ : 446-449. http://cat.inist.fr/?aModele $=$ afficheN\&cpsidt $=1500$ 3505

14. Miller, A. and K.H. Engel, 2006. Content of $\gamma$ oryzanol and composition of steryl ferulates in brown rice (Oryza sativa L.) of European origin. J. Agric. Food Chem., 54: 8127-8133. http://cat.inist.fr/?aModele $=$ afficheN\&cpsidt $=1820$ 3727

15. Alam, M.Z., T. Stuchbury, R.E.L. Naylor and M.A. Rashid, 2003. Water uptake and germination pattern of rice Seeds under isoosmotic solution $\mathrm{NaCl}$ and peg, different concentration of $\mathrm{CaCl}_{2}$ and combination of $\mathrm{NaCl}$ and $\mathrm{CaCl}_{2}$. Pakistan $\mathrm{J}$. Biol. Sci., 6: 1059-1066. http://www.scialert.net/qredirect.php?doi=pjbs.20 03.1059.1066\&linkid $=$ pdf 